\title{
Recombinant human brain natriuretic peptide attenuates LPS-induced cellular injury in human fetal lung fibroblasts via inhibiting MAPK and NF-кB pathway activation
}

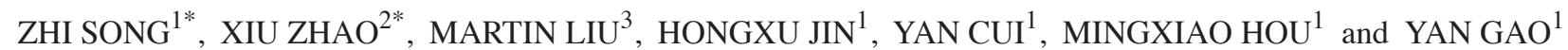 \\ ${ }^{1}$ Department of Emergency and Critical Care Medicine, The General Hospital of Shenyang Military, Shenyang, Liaoning 110016; \\ ${ }^{2}$ Department of Oral Medicine, The Shenyang Medical College, Shenyang, Liaoning 110034, P.R. China; \\ ${ }^{3}$ Division of Pulmonary, Critical Care, Sleep and Allergy Medicine, Department of Internal Medicine, \\ University of Nebraska Medical Center, Omaha, NE 68198, USA
}

Received April 9, 2015; Accepted February 19, 2016

DOI: $10.3892 / \mathrm{mmr} .2016 .5400$

\begin{abstract}
Inflammatory responses are vital in lung injury diseases, particularly acute respiratory distress syndrome (ARDS). Recombinant human brain natriuretic peptide (rhBNP) has been shown to exhibit anti-inflammatory effects in vivo in our previous studies. The present study aimed to investigate the mechanisms underlying the anti-inflammatory effects of rhBNP on lipopolysaccharide (LPS)-induced human fetal lung fibroblasts (HFL-1). The results showed that LPS induced a significant increase in the leakage of lactate dehydrogenase and the secretion of interleukin (IL)-1 $\beta$. Activation of p38, extracellular-signal regulated kinase (ERK) 1/2, c-Jun NH2-terminal kinase (JNK) mitogen-activated protein kinases (MAPK)s, and nuclear factor (NF)- $\kappa$ B in HFL-1 cells was also observed following treatment with LPS. Treatment with rhBNP $(0.1 \mu \mathrm{M})$ reduced the production of IL-1 $\beta$ at the protein and mRNA levels. Moreover, rhBNP decreased the phosphorylation of p38, ERK1/2 and JNK induced by LPS. However, the JNK inhibitor, SP600125, significantly inhibited LPS-induced IL-1 $\beta$ production. These results indicate that the inhibition of IL-1 $\beta$ by may dependent upon the JNK signaling pathway. The LPS-induced NF- $\kappa \mathrm{B}$ activation was also suppressed by rhBNP, and IL- $1 \beta$ production was inhibited by the $N F-\kappa B$ inhibitor. Furthermore, $N F-\kappa B$ activation was attenuated by the JNK inhibitor, indicating that NF- $\kappa \mathrm{B}$ activation was dependent on the JNK signaling pathway. The present
\end{abstract}

Correspondence to: Professor Yan Gao, Department of Emergency and Critical Care Medicine, The General Hospital of Shenyang Military, 83 Wen-Hua Road, Shen-He, Shenyang, Liaoning 110016, P.R. China

E-mail: gaoyan7879@163.com

*Contributed equally

Key words: recombinant human brain natriuretic peptide, human fetal lung fibroblasts, lipopolysaccharide, nuclear factor- $\kappa \mathrm{B}$, mitogen-activated protein kinase study suggests that rhBNP exhibits an anti-inflammatory effect on LPS-induced HFL-1 cell injury via the inhibition of MAPK and $\mathrm{NF}-\kappa \mathrm{B}$ signaling pathways and may exhibit therapeutic potential for acute lung injury and ARDS.

\section{Introduction}

Acute respiratory distress syndrome (ARDS) is caused by a variety of insults, such as sepsis, major trauma, pneumonia, transfusions and aspiration of gastric contents. It is associated with a high rate of mortality according to the most recent report of the ARDS Network clinical trials (1). Sepsis is the most common predisposing factor of ARDS and is characterized by systemic inflammation in response to microbial toxins, such as lipopolysaccharide (LPS), a component of the cell wall of gram-negative bacteria. Cellular characteristics of ARDS include loss of alveolar-capillary membrane integrity, excessive trans-epithelial neutrophil migration and release of pro-inflammatory cytotoxic mediators (2). Fibroblasts are important in normal and pathological repair (3). Fibroblasts are also involved in the inflammatory reaction and exhibit a critical role in the switch from acute inflammation to tissue repair (3). In addition, lung fibroblast migration and proliferation occur early after lung injury and are required for ongoing lung healing $(4,5)$. Therefore, protecting lung fibroblasts and ameliorating their inflammatory reactions has been suggested to be a promising method for alleviating lung injury.

Brain natriuretic peptide (BNP) is a member of the atria natriuretic peptide (ANP) family, and was first isolated from porcine brains (6). As a cardiac hormone predominantly produced by ventricular myocytes, BNP has been used as a biomarker for heart failure $(7,8)$. It has vasodilatory and natriuretic functions that counteract vasoconstriction and the fluid-retaining effect of the rennin-angiotensin system. As a man-made peptide developed through gene engineering, recombinant human brain natriuretic peptide (rhBNP) is widely used clinically for the treatment of decompensated heart failure (9). Most recently, rhBNP has also been administered intravenously for use in critical care units such as guiding fluid therapy, predicting clinical outcomes of critical illness 
including sepsis. BNP level may be a good indicator of cardiac preload in patients with high volume load, and serve as a powerful predictor of mortality in patients with sepsis (10-12). In our previous studies, it was identified that rhBNP exhibited protective effects on certain organs, including lung (13-15). However, the underlying mechanism remains unclear, and little information is available regarding the effect of rhBNP on inflammatory responses in HFL-1 human fetal lung fibroblasts. Therefore, the present study investigated the effects of rhBNP on inflammatory molecules and signaling pathways in HFL-1 cells challenged by LPS.

\section{Materials and methods}

Materials. rhBNP was obtained from Nuodikang Biological Pharmaceutical Company Ltd. (Chengdu, China). LPS and fetal calf serum (FCS) was purchased from Sigma-Aldrich (St. Louis, MO, USA). Tissue culture supplements and medium were purchased from Thermo Fisher Scientific, Inc. (Waltham, MA, USA). All other materials and antibodies were purchased from Takara Biotechnology Co., Ltd. (Dalian, China). Experiments were conducted according to the National Institutes of Health (NIH) guidelines and approved by the ethics committee of the General Hospital of Shenyang Military District (Shenyang, China).

Cell culture. HFL-1 cells were obtained from the Shanghai Institute of Cell Biology, Chinese Academy of Sciences (Shanghai, China). The cells were cultured in $100-\mathrm{mm}$ tissue culture dishes with Dulbecco's modified Eagle's medium (DMEM) supplemented with $10 \% \mathrm{FCS}, 50 \mathrm{mg} / \mathrm{ml}$ penicillin, $50 \mathrm{mg} / \mathrm{ml}$ streptomycin, and $0.25 \mathrm{mg} / \mathrm{ml}$ Fungizone. The cells were passaged every 3 to 5 days. Fibroblasts used in these studies were between cell passages 10 and 20 .

Groups and treatments. Cells were divided into the following groups: Control group, rhBNP $(0.1 \mu \mathrm{M})$ group, LPS $(1 \mu \mathrm{g} / \mathrm{ml})$ group, LPS $(1 \mu \mathrm{g} / \mathrm{ml})+\operatorname{rhBNP}(0.1 \mu \mathrm{M})$ group, and LPS $(1 \mu \mathrm{g} / \mathrm{ml})+\operatorname{rhBNP}(0.1 \mu \mathrm{M})+$ inhibitor group. For all experiments, cells were plated in 6-well plates and grown to $80 \%$ confluence. For the control and control + rhBNP groups, HFL-1 cells were not exposed to LPS. The cells were serum deprived for $24 \mathrm{~h}$ in DMEM medium containing 10\% FBS prior to the addition of LPS and/or $0.1 \mu \mathrm{M}$. SB203580 (p38 inhibitor, $20 \mu \mathrm{M}$ ), SP600125 [c-Jun NH2-terminal kinase (JNK) inhibitor, $25 \mu \mathrm{M}$ ], PD098059 [extracellular signal-regulated kinase $1 / 2$ (ERK1/2) inhibitor, $5 \mu \mathrm{M})$ or pyrrolidine dithiocarbamate [PDTC; nuclear factor (NF)- $\mathrm{KB}$ inhibitor, $10 \mu \mathrm{M}$ ) was added 30 min prior to LPS exposure, respectively. The cells were then incubated with LPS $(1 \mu \mathrm{g} / \mathrm{ml})$ for $0,2,4$, $6,8,12$, and $24 \mathrm{~h}$.

Lactate dehydrogenase ( $\mathrm{LDH}$ ) release assays. Following treatment, LDH release in the medium was measured using a previously described method (16). The absorbance values were read using a microplate reader (Bio-Rad Laboratories, Hercules, CA, USA) at $440 \mathrm{~nm}$, and the results of the absorbance from the test wells were expressed as a percentage of the control wells. Results from a single experiment are reported. Similar data were obtained in six independent experiments.
Measurement of interleukin (IL)-1 $\beta$ secretion. The level of IL-1 $\beta$ secretion in culture media was determined by an enzyme-linked immunosorbent assay kit (R\&D Systems, Inc., Minneapolis, MN, USA) according to the manufacturer's instructions. Concentrations were calculated with reference to the standard curve.

Quantitative analysis of the IL-I $\beta$ mRNA expression. Total RNA extraction was isolated using TRIzol Reagent (Invitrogen; Thermo Fischer Scientific, Inc.) according to the manufacturer's instructions. An RNA denaturation mix consisting of isolated RNA, nuclease-free water and oligo dT primers was used. cDNA was synthesized using a reverse transcription kit (TransGen Biotech, Inc., Beijing, China) according to the manufacturer's instructions. Following reverse transcription, quantitative analysis of the IL- $1 \beta$ mRNA expression was analyzed by the real-time polymerase chain reaction (PCR) method. The following primers (Takara Biotechnology Co., Ltd.) were used: Forward, 5'-ATGCCT CGTGCTGTCTGACC-3' and reverse, 5'-CCATCTTTAGGA AGACACGGGTT-3' for IL-1 $\beta$; and forward, 5'-ATGTGCCGG ACCTTGGAAG-3' and reverse, 5'-CCTCGGGTTAGCTGA GAGATCA-3' for glyceraldehyde 3-phosphate dehydrogenase (GAPDH). PCR assays were performed in duplicate on the 7500 real-time PCR machine (Applied Biosystems; Thermo Fisher Scientific, Inc.). The cycling conditions were as follows: Incubation for $2 \mathrm{~min}$ at $50^{\circ} \mathrm{C}$ followed by another incubation step at $95^{\circ} \mathrm{C}$ for $10 \mathrm{~min}, 15 \mathrm{sec}$ at $95^{\circ} \mathrm{C}$ and $1 \mathrm{~min}$ at $60^{\circ} \mathrm{C}$ for 40 cycles. Reaction specificity was evaluated by melting curve analysis, which was performed by heating the plate from $55^{\circ} \mathrm{C}$ to $95^{\circ} \mathrm{C}$ and measuring SYBR Green I (Takara Biotechnology Co., Ltd.) dissociation from the amplicons. The calculation of quantification cycles (Cq values) and further analysis of these data were performed by the Sequence Detector software (version 1.2.3; Syngene, Cambridge, UK). The relative expression of mRNA in each sample was quantified and normalized to the GAPDH mRNA levels by the $2^{-\Delta \Delta \mathrm{Cq}} \operatorname{method}(17)$.

Western blot analysis. HFL-1 cells were collected in lysis buffer and centrifuged at $1,500 \mathrm{xg}$ for $5 \mathrm{~min}$ at $5^{\circ} \mathrm{C}$. Total cellular protein in the supernatant was determined using the bicinchoninic acid (Takara Biotechnology Co., Ltd.) method. Equal quantities of protein ( $40 \mu \mathrm{g}$ per lane) were separated on $10 \%$ sodium dodecyl sulfate-polyacrylamide gels (Takara Biotechnology Co., Ltd.) and electrically transferred to nitrocellulose membranes (Takara Biotechnology Co., Ltd.) at $80 \mathrm{~V}$ at $4^{\circ} \mathrm{C}$ for $2 \mathrm{~h}$. The nitrocellulose membranes were blocked with $5 \%$ non-fat dry milk, and then blots were incubated overnight at $4^{\circ} \mathrm{C}$ with the following primary monoclonal antibodies: Rabbit anti-p-p38 (cat no. 10359), anti-p38 (cat no. 10360), anti-p-JNK (cat no. 18295), anti-JNK (cat no. 18296), anti-ERK1/2 (cat no. 10621), anti-p-ERK1/2 (cat no. 10620), NF-кB p65 (cat no. 18667), anti-p-IкB (cat no. 18669) or anti- $\beta$-actin antibody (cat no. 21765) (all 1:1,000; Cell Signaling Technology, Danvers, MA, USA). The following day, the membranes were washed in phosphate-buffered saline with Tween-20 (Takara Biotechnology Co., Ltd.), incubated with horseradish-peroxidase-conjugated goat anti-rabbit second antibody Takara Biotechnology Co., Ltd.) and washed again. Signals were visualized by enhanced chemiluminescence (Takara Biotechnology 

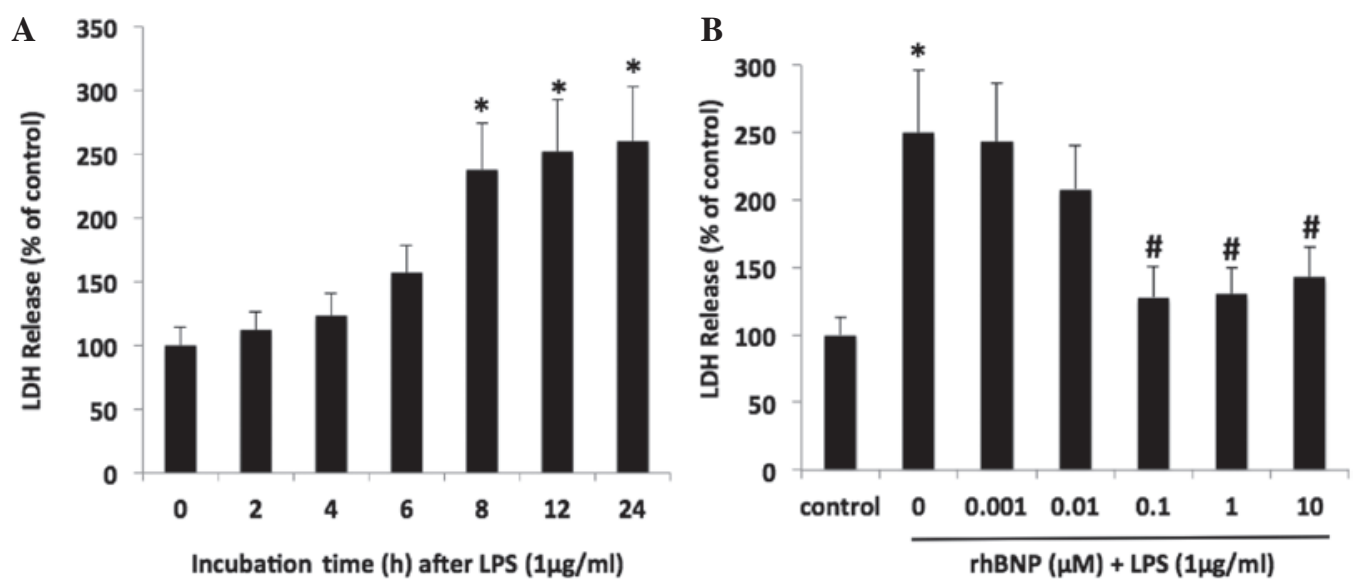

Figure 1. Effects of rhBNP on LPS-induced cell injury in HFL-1 cells. Cell injury was measured by a lactate dehydrogenase release assay. (A) Cell injury was determined at different time points following treatment with LPS. (B) rhBNP at the indicated concentrations was applied to HFL-1 cells 30 min prior to treatment with LPS for $24 \mathrm{~h}$. ${ }^{*} \mathrm{P}<0.05$ vs. control, ${ }^{*} \mathrm{P}<0.05$ vs. the LPS group $(0 \mu \mathrm{m}$ rhBNP). rhBNP, recombinant human brain natriuretic peptide; LPS, lipopolysaccharide; LDH, lactate dehydrogenase.
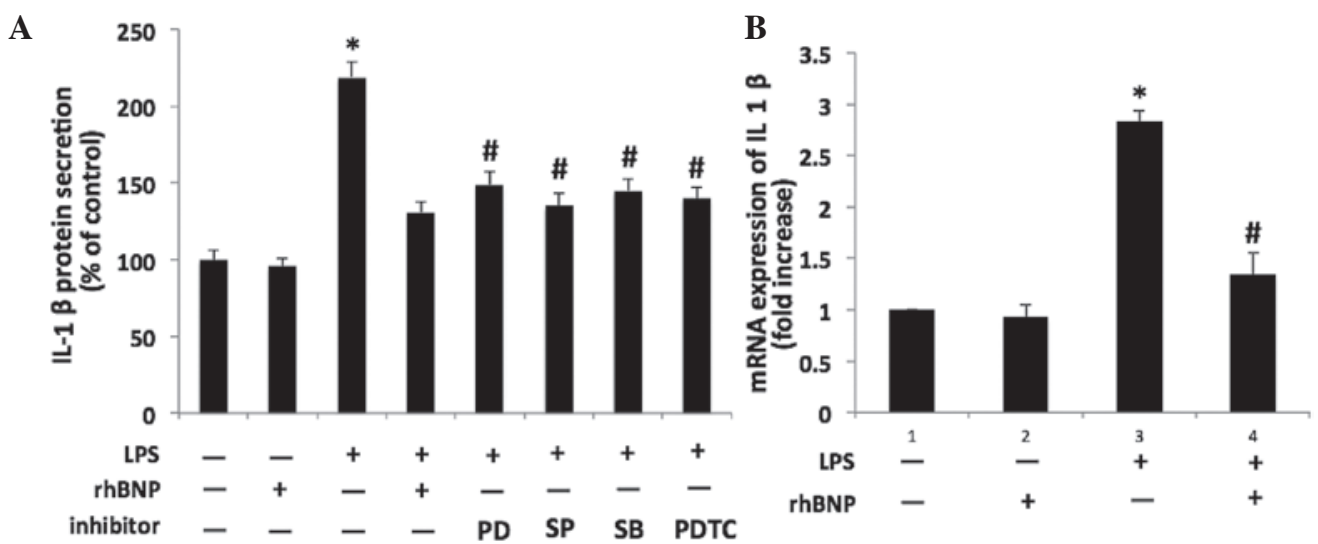

Figure 2. Effects of LPS, rhBNP and mitogen-activated protein kinase pathway inhibitors on secretion of IL-1 $\beta$ in HFL-1 cells. (A) IL-1 $\beta$ protein levels in the culture media of HFL-1 cells with or without treatment with LPS, rhBNP, p38 inhibitor (SB203580, $20 \mu \mathrm{M}$ ), c-Jun NH2-terminal kinase inhibitor (SP600125, $25 \mu \mathrm{M}$ ), extracellular signal-regulated kinase 1/2 inhibitor (PD098059, $5 \mu \mathrm{M}$ ) and nuclear factor- $\mathrm{kB}$ inhibitor (PDTC, $10 \mu \mathrm{M})$ for $24 \mathrm{~h}$ were analyzed by enzyme-linked immunosorbent assay. (B) Effects of LPS and rhBNP on IL-1 $\beta$ mRNA expression in HFL-1 cells were determined by reverse transcription-quantitative polymerase chain reaction. ${ }^{~} \mathrm{P}<0.05$ vs. the control group, ${ }^{~} \mathrm{P}<0.05$ vs. the LPS group. LPS, lipopolysaccharide; rhBNP, recombinant human brain natriuretic peptide; LDH, lactate dehydrogenase; IL, interleukin.

Co., Ltd.). The intensity of each band was measured and analyzed with the Quantity One software (version 4.1; Bio-Rad Laboratories).

Statistical analysis. All quantitative data are expressed as the mean \pm standard error of the mean. Numerical data were performed using one-way analysis of variance with Tukey's post hoc test. Statistical analysis was performed using SPSS (version 15; SPSS, Inc., Chicago, IL, USA ). P $<0.05$ was considered to indicate a statistically significant difference. Each experiment was performed at least three times.

\section{Results}

rhBNP attenuates LPS-induced cell injury. To evaluate LPS-induced cell injury, the release of LDH into the medium was measured. The LDH leakage was increased in a time-dependent manner following treatment with LPS $(\mathrm{P}<0.05$ vs. control, Fig. 1A). In addition, the effect of rhBNP on LDH release in the
HFL-1 cells was greatest at concentrations of $0.1,1$ and $10 \mu \mathrm{M}$ (Fig. 1B). rhBNP at a dose of $0.1 \mu \mathrm{M}$ was administered in the following experiments. These results demonstrated that rhBNP could attenuate LPS-induced cell injury.

rhBNP reduces the IL-1 $\beta$ level in HFL-1 cells. Compared with the control group, the level of IL-1 $\beta$ in the culture medium was significantly increased after $24 \mathrm{~h}$ exposure to LPS $(\mathrm{P}<0.05)$. As shown in Fig. 2A, LPS-induced IL-1 $\beta$ secretion was significantly inhibited by $0.1 \mu \mathrm{M}$ rhBNP (P<0.05 vs. LPS). Moreover, pretreatment with the p38 inhibitor SB203580, JNK inhibitor SP600125, ERK1/2 inhibitor PD098059, or NF- $\mathrm{KB}$ inhibitor PDTC inhibited the LPS-induced increase in the IL-1 $\beta$ level $(\mathrm{P}<0.05$ vs. LPS). For IL-1 $\beta$ mRNA expression, the IL- $1 \beta$ level was significantly induced by $0.1 \mu \mathrm{M}$ rhBNP when compared with the LPS group $(\mathrm{P}<0.05$, Fig. $2 \mathrm{~B})$.

rhBNP suppresses the LPS-induced phosphorylation of p38, JNK, and ERK1/2 MAP kinases. Protein expression of 

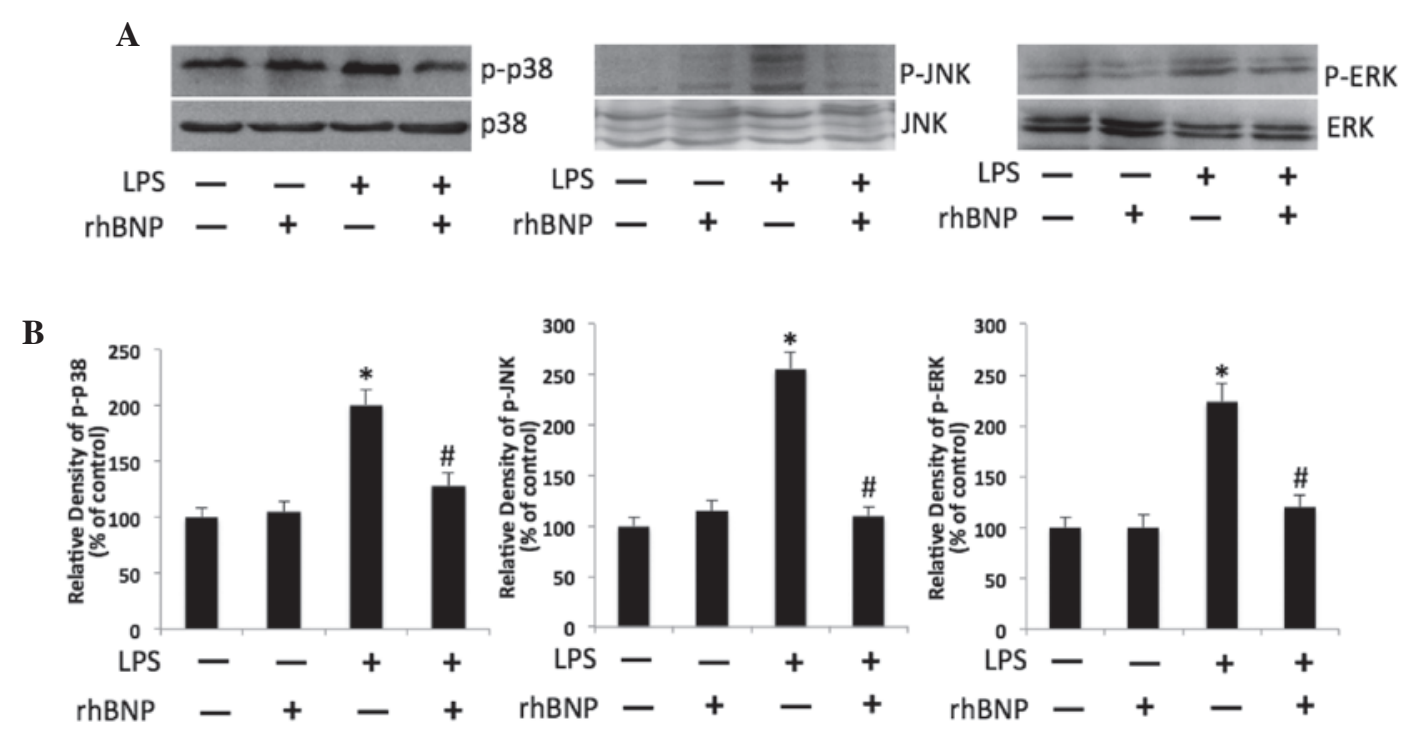

Figure 3. Effects of rhBNP and LPS on phosphorylation of p38, JNK and ERK1/2 in HFL-1. (A) Expression of p-p38, p38, p-JNK, JNK, p-ERK1/2 and ERK1/2 was detected by western blot analysis. Immunostaining of $\mathrm{p} 38$, JNK, and ERK1/2 served as respective controls. (B) Bar graphs represents semi-quantitative densitometry from western blot analysis. ${ }^{*} \mathrm{P}<0.05$ vs. the control group, ${ }^{\prime} \mathrm{P}<0.05$ vs. the LPS group. rhBNP, recombinant human brain natriuretic peptide; LPS, lipopolysaccharide; LDH, lactate dehydrogenase; p-, phosphorylate; JNK, c-Jun NH2-terminal kinase; ERK1/2 extracellular signal-regulated kinase 1/2.

key molecules in the intracellular mitogen-activated protein kinases signaling pathways, p-p38, p-JNK, and p-ERK1/2 were detected using western blot analysis. The results showed that the expression of p-p38, p-JNK and p-ERK1/2 was significantly increased in the LPS group $(\mathrm{P}<0.05$ vs. control), whereas treatment with rhBNP significantly suppressed the expression of p-p38, p-JNK and p-ERK1/2 when compared with the LPS group $(\mathrm{P}<0.05$, Fig. 3$)$.

rhBNP suppresses LPS-induced NF- $\kappa B$ activation via inhibition of JNK phosphorylation. The activity of the molecules in the NF- $\mathrm{KB}$ signaling pathway was determined by measuring the levels of the NF- $\kappa B$ p 65 and $p-I \kappa B$ proteins in the cellular extract of HFL-1 cells. The expression of NF- $\kappa B$ p65 and p-IкB were increased significantly in the LPS group $(\mathrm{P}<0.05$ vs. control); treatment with rhBNP significantly inhibited the LPS-induced increase of NF- $\kappa B$ p65 and $\mathrm{p}-\mathrm{I} \kappa \mathrm{B}(\mathrm{P}<0.05$ vs. LPS); furthermore, pretreatment with the JNK inhibitor SP600125 attenuated the increase of NF- $\kappa B$ p65 and p-IкB (P<0.05 vs. LPS) (Fig. 4).

\section{Discussion}

Our previous studies have demonstrated that rhBNP prevents LPS-induced acute lung injury in a dog model and may be associated with adjusting the levels of endogenous antioxidant enzymes (14). However, the effects of rhBNP on HFL-1 cells in terms of inflammation have not yet been described. rhBNP is known to exert its anti-inflammatory activity in various organs (18-21). Therefore, further investigation of the mechanism by which rhBNP influences LPS-induced human lung fibroblasts has important clinical implications. Consistently, the results of the present study indicate that rhBNP may have anti-inflammatory effects on LPS-induced HFL-1 cells via inhibiting MAPK and NF-KB pathways.

It is generally known that fibroblasts are important in inflammation resolution following cell injury (22). Lung fibroblasts are important responsive and regulatory components of lung inflammation induced by LPS and have also been shown to generate inflammatory cytokines, such as IL-1 $\beta$, IL- 8 , and tumor necrosis factor- $\alpha$, which have been demonstrated to mediate lung injury $(23,24)$. Moreover, IL-1 $\beta$ is an important mediator of inflammation and activates the NF- $\mathrm{KB}$ pathway in cells (25). LDH is normally retained within cells; however, once cells are damaged LDH is released into the medium. Thus, $\mathrm{LDH}$ release is an indicator of the integrity of the cell membrane. This study demonstrated that treatment with LPS resulted in a significant increase in the levels of LDH in the culture medium. The current study aimed to demonstrate the therapeutic effect of rhBNP on LPS-induced cell injury in vitro. The results indicated that rhBNP significantly ameliorated the LDH release after LPS treatment, showing its protective effects on cell injury. The effect of rhBNP on the secretion of the key inflammatory cytokine IL- $1 \beta$ was then detected. The results showed that the increased protein and mRNA expression of IL-1 $\beta$ induced by LPS was significantly reduced following treatment with rhBNP.

BNP is a type of neuroendocrine hormone and can dilate blood vessels selectively, and aid sodium and urine excretion. RhBNP is a freeze-dried peptide produced by genetic recombination. The amino acid sequence of rhBNP is the same as endogenous BNP obtained from humans (26). rhBNP can be combined with natriuretic peptide receptor embedded in effector cell membrane and activate the combination of sweet bird cyclase which is connected to it. Furthermore, it enhances the levels of cyclic guanosine monophosphate (cGMP) in effector cells. The elevated cGMP acts on protein kinase $\mathrm{G}$ on the capillary endothelial cell membrane, which results in dephosphorylation of myosin light chains, vascular smooth muscle contraction and relaxation and extended vessels (27). Therefore, our recent studies indicated that rhBNP exhibited anti-inflammatory effects on the kidney and intestinal tissues in animal models of endotoxin-induced injuries $(13,15)$. 


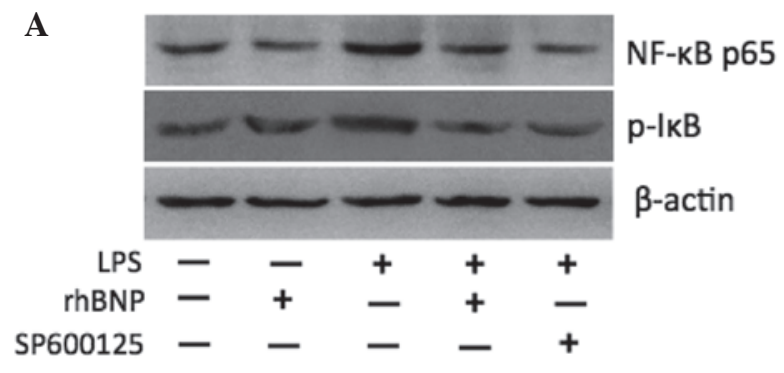

B
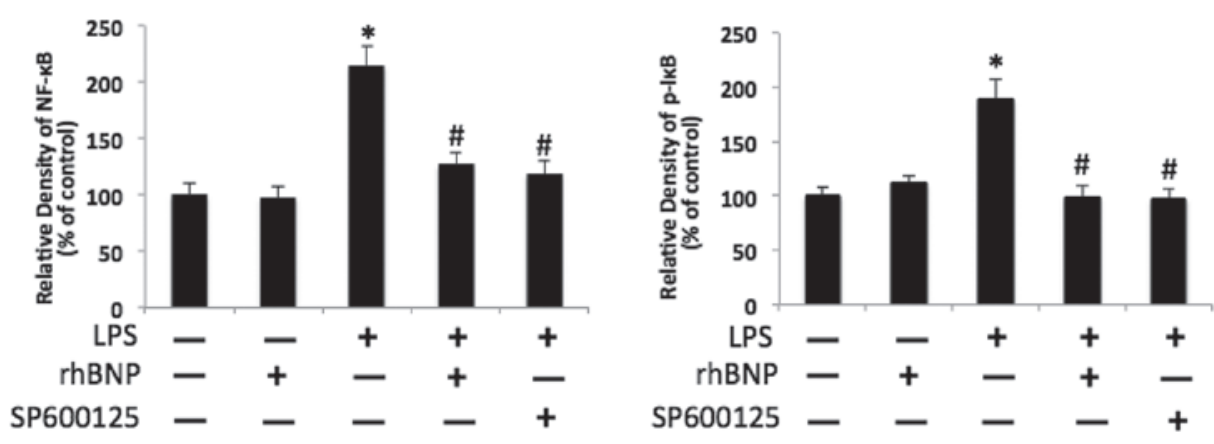

Figure 4. Effects of LPS, rhBNP and c-Jun NH2-terminal kinase inhibitor (SP600125) on phosphorylation of proteins in the intracellular NF-kB signaling pathway. (A) Expression of NF-кB p65 and p-IкB were analyzed by western blot analysis, and $\beta$-actin was used as a control. (B) Bar graphs represent semi-quantitative densitometry from western blot analysis. ${ }^{~} \mathrm{P}<0.05$ vs. the control group, ${ }^{\text {}} \mathrm{P}<0.05$ vs. the LPS group. rhBNP, recombinant human brain

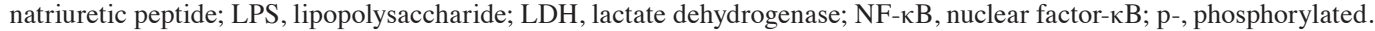

MAPK is vital in cell growth, differentiation, proliferation and apoptosis as an essential component of signal transduction (28). Certain studies have indicated that members of the MAPK signaling pathway, including ERK, p38 MAPK and JNK, are important in signal transduction pathways activated by stimuli and mediate a number of physiological and pathological changes in cell function (29). The MAPK pathway is also the signal cascade pathway of pro-inflammatory molecules and regulates the inflammatory response through NF- $\mathrm{KB}$ activation $(30,31)$. In order to determine the effect of rhBNP in lung fibroblasts under LPS stimulation, the NF-кB pathway was investigated as it is involved in numerous cellular processes, particularly inflammation $(32,33)$. Moreover, activation of NF- $\kappa \mathrm{B}$ by cytokines, such as IL-1 $\beta$, can promote inflammatory mediator production (32). Our previous study and certain recent studies have shown that inhibition of the NF- $\mathrm{B}$ pathway ameliorated organ injury in animal models, which probably occurred via the inactivation of NF- $\kappa B$ p65 and further inhibition of inflammation $(13,34,35)$. In the present study, activation of p38, ERK1/2 and JNK was detected in HFL-1 cells following treatment with LPS, and rhBNP treatment was shown to ameliorate this effect. In addition, the JNK inhibitor decreased IL-1 $\beta$ secretion in LPS-induced HFL-1 cells. Thus, these results indicate that the inhibition of the MAPK signaling pathway is the mechanism underlying the inhibition of the secretion of the inflammatory cytokines following treatment with rhBNP.

$\mathrm{NF}-\mathrm{KB}$ is primarily found in the cytoplasm in an inactive non-DNA-binding form that is associated with the inhibitor protein I $\mathrm{KB}$ in unstimulated cells. Following simulation, $\mathrm{NF}-\kappa \mathrm{B}$ translocates into the nucleus and regulates the transcription of genes, including those coding for the inflammatory molecules (36). Previous studies have shown that sustained NF- $\mathrm{\kappa B}$ activation is correlated with lung injury, and rhBNP was also involved in inhibiting inflammatory processes $(17,37)$. The results of the present study indicated that LPS-induced IL-1 $\beta$ elevation was significantly inhibited by the NF- $\kappa$ B specific inhibitor PDTC, which demonstrated that an increase in LPS-induced IL-1 $\beta$ may depend on the $\mathrm{NF}-\kappa \mathrm{B}$ signaling pathway. Furthermore, NF- $\mathrm{KB}$ was significantly activated in LPS-induced HFL-1 cells as shown by increased expression of NF- $\kappa \mathrm{B}$ p 65 and $\mathrm{p}-\mathrm{I} \kappa \mathrm{B}$. However, rhBNP treatment significantly inhibited the activation of $\mathrm{NF}-\kappa \mathrm{B}$ that was induced by LPS. These results showed that the inhibitory effect of rhBNP on the LPS-induced IL- $1 \beta$ elevation was also dependent on the NF- $\kappa$ B activation. Furthermore, the JNK inhibitor attenuated the NF- $\mathrm{KB}$ activation that was induced by LPS, which suggested that LPS-induced NF- $\mathrm{KB}$ activation may be dependent on JNK activation.

In conclusion, the results of this study demonstrated that rhBNP could inhibit HFL-1 cell injury induced by LPS by inhibiting the MAPK and NF- $\mathrm{KB}$ signaling pathways. These findings indicate that rhBNP protects HFL-1 cell injury in response to endotoxin insult, and that rhBNP may be used not only as a diagnostic or prognostic biomarker in critical care units, but also as a novel therapeutic agent to ameliorate lung injury.

\section{Acknowledgements}

This study was supported by the Postdoctoral Science Foundation, China (grant no. 2014M552693), and Science and Technology Project of Liaoning, China (grant no. 2013225089) awarded to Dr Zhi Song. 


\section{References}

1. No authors listed: Ventilation with lower tidal volumes as compared with traditional tidal volumes for acute lung injury and the acute respiratory distress syndrome. The Acute Respiratory Distress Syndrome Network. N Engl J Mes 342: 1301-1308, 2000.

2. Matthay MA and Zimmerman GA: Acute lung injury and the acute respiratory distress syndrome: Four decades of inquiry into pathogenesis and rational management. Am J Respir Cell Mol Biol 33: 319-327, 2005.

3. Buckley CD, Pilling D, Lord JM, Akbar AN, Scheel-Toellner D and Salmon M: Fibroblasts regulate the switch from acute resolving to chronic persistent inflammation. Trends Immunol 22: 199-204, 2001.

4. Horowitz JC, Cui Z, Moore TA, Meier TR, Reddy RC, Toews GB, Standiford TJ and Thannickal VJ: Constitutive activation of prosurvival signaling in alveolar mesenchymal cells isolated from patients with nonresolving acute respiratory distress syndrome. Am J Physiol Lung Cell Mol Physiol 290: L415-L425, 2006.

5. Marshall RP, Bellingan G, Webb S, Puddicombe A, Goldsack N, McAnulty RJ and Laurent GJ: Fibroproliferation occurs early in the acute respiratory distress syndrome and impacts on outcome. Am J Respir Crit Care Med 162: 1783-1788, 2000.

6. Maekawa K, Sudoh T, Furusawa M, Minamino N, Kangawa K, Ohkubo H, Nakanishi S and Matsuo H: Cloning and sequence analysis of cDNA encoding a precursor for porcine brain natriuretic peptide. Biochem Biophys Res Commun 157: 410-416, 1988.

7. Mueller C, Scholer A, Laule-Kilian K, Martina B, Schindler C, Buser P, Pfisterer M and Perruchoud AP: Use of B-type natriuretic peptide in the evaluation and management of acute dyspnea. N Engl J Med 350: 647-654, 2004.

8. Lehr HA, Guhlmann A, Nolte D, Keppler D and Messmer K: Leukotrienes as mediators in ischemia-reperfusion injury in a microcirculation model in the hamster. J Clin Invest 87: 2036-2041, 1991.

9. Burger MR and Burger AJ: BNP in decompensated heart failure: Diagnostic, prognostic and therapeutic potential. Curr Opin Investig Drugs 2: 929-935, 2001

10. Yamanouchi S, Kudo D, Endo T, Kitano Y and Shinozawa Y: Blood N-terminal proBNP as a potential indicator of cardiac preload in patients with high volume load. Tohoku J Exp Med 221: 175-180, 2010.

11. Wang F, Wu Y, Tang L, Zhu W, Chen F, Xu T, Bo L, Li J and Deng $X$ : Brain natriuretic peptide for prediction of mortality in patients with sepsis: A systematic review and meta-analysis. Crit Care 16: R74, 2012.

12. Li N, Zhang Y, Fan S, Xing J and Liu H: BNP and NT-proBNP levels in patients with sepsis. Front Biosci (Landmark Ed) 18: 1237-1243, 2013

13. Yang H, Song Z, Jin H, Cui Y, Hou M and Gao Y: Protective effect of rhBNP on intestinal injury in the canine models of sepsis. Int Immunopharmacol 19: 262-266, 2014.

14. Song Z, Cui Y, Ding MZ, Jin HX and Gao Y: Protective effects of recombinant human brain natriuretic peptide against LPS-Induced acute lung injury in dogs. Int Immunopharmacol 17: 508-512, 2013.

15. Li N, Jin HX, Song Z, Bai CZ, Cui Y and Gao Y: Protective effect of recombinant human brain natriuretic peptide on acute renal injury induced by endotoxin in canines. Cell Biochem Biophys 70: 1317-1324, 2014.

16. Xu B, Xu ZF and Deng Y: Effect of manganese exposure on intracellular $\mathrm{Ca}^{2+}$ homeostasis and expression of NMDA receptor subunits in primary cultured neurons. Neurotoxicology 30: 941-949, 2009.

17. Livak KJ and Schmittgen TD: Analysis of relative gene expression data using real-time quantitative PCR and the 2(-Delta Delta C(T)) Method. Methods 25: 402-408, 2001.

18. Chiurchiù V, Izzi V, D'Aquilio F, Carotenuto F, Di Nardo $\mathrm{P}$ and Baldini PM: Brain natriuretic peptide (BNP) regulates the production of inflammatory mediators in human THP-1 macrophages. Regul Pept 148: 26-32, 2008.
19. James ML, Wang H, Venkatraman T, Song P, Lascola CD and Laskowitz DT: Brain natriuretic peptide improves long-term functional recovery after acute CNS injury in mice. J Neurotrauma 27: 217-228, 2010.

20. Kiemer AK and Vollmar AM: The atrial natriuretic peptide regulates the production of inflammatory mediators in macrophages. Ann Rheum Dis 60 (Suppl 3): iii68-iii70, 2001.

21. Moro C, Klimcakova $\mathrm{E}$, Lolmède K, Berlan M, Lafontan M, Stich V, Bouloumié A, Galitzky J, Arner P and Langin D: Atrial natriuretic peptide inhibits the production of adipokines and cytokines linked to inflammation and insulin resistance in human subcutaneous adipose tissue. Diabetologia 50: 1038-1047, 2007.

22. Serhan CN, Brain SD, Buckley CD, Gilroy DW, Haslett C, O'Neill LA, Perretti M, Rossi AG and Wallace JL: Resolution of inflammation: State of the art, definitions and terms. FASEB J 21: 325-332, 2007.

23. Chen Y, Zhou X and Rong L: Analysis of mechanical ventilation and lipopolysaccharide-induced acute lung injury using DNA microarray analysis. Mol Med Rep 11: 4239-4245, 2015.

24. Lu Z, Ma Y, Zhang S, Liu F, Wan M and Luo J: Transforming growth factor-betal small interfering RNA inhibits growth of human embryonic lung fibroblast HFL-I cells in vitro and defends against radiation-induced lung injury in vivo. Mol Med Rep 11: 2055-2061, 2015.

25. Wang $\mathrm{Z}$ and Tai HH: Interleukin-1 beta and dexamethasone regulate gene expression of prostaglandin $\mathrm{H}$ synthase- 2 via the NF- $\kappa \mathrm{B}$ pathway in human amnion derived WISH cells. Prostaglandins Leukot Essent Fatty Acids 59: 63-69, 1998.

26. Chen HH, Grantham JA, Schirger JA, Jougasaki M, Redfield MM and Burnett JC Jr: Subcutaneous administration of brain natriuretic peptide in experimental heart failure. J Am Coll Cardiol 36: 1706-1712, 2000.

27. Burger AJ: A review of the renal and neurohormonal effects of B-type natriuretic peptide. Congest Heart Fail 11: 30-38, 2005.

28. Craig EA, Stevens MV, Vaillancourt RR and Camenisch TD: MAP3Ks as central regulators of cell fate during development. Dev Dyn 237: 3102-3114, 2008.

29. Song HY, Lee JA, Ju SM, Yoo KY, Won MH, Kwon HJ, Eum WS, Jang SH, Choi SY and Park J: Topical transduction of superoxide dismutase mediated by HIV-1 Tat protein transduction domain ameliorates 12-O-tetradecanoylphorbol-13-acetate (TPA)-induced inflammation in mice. Biochem Pharmacol 75: 1348-1357, 2008

30. Chen Q, Huang Y, Yang Y and Qiu H: Acid-induced cell injury and death in lung epithelial cells is associated with the activation of mitogen-activated protein kinases. Mol Med Rep 8: 565-570, 2013.

31. Yoon WJ, Moon JY, Song G, Lee YK, Han MS, Lee JS, Ihm BS, Lee WJ, Lee NH and Hyun CG: Artemisia fukudo essential oil attenuates LPS-induced inflammation by suppressing NF-kappaB and MAPK activation in RAW 264.7 macrophages. Food Chem Toxicol 48: 1222-1229, 2010.

32. Beinke S and Ley SC: Functions of NF-kappaB1 and NF-kappaB2 in immune cell biology. Biochem J 382: 393-409, 2004.

33. Beinke $S$, Robinson MJ, Hugunin $M$ and Ley SC: Lipopolysaccharide activation of the TPL-2/MEK/extracellular signal-regulated kinase mitogen-activated protein kinase cascade is regulated by IkappaB kinase-induced proteolysis of NF-kappaB1 p105. Mol Cell Biol 24: 9658-9667, 2004.

34. Zhou Y, Zhang X, Tan M, Zheng R and Zhao L: The effect of $\mathrm{NF}-\kappa \mathrm{B}$ antisense oligonucleotide on transdifferentiation of fibroblast in lung tissue of mice injured by bleomycin. Mol Biol Rep 41: 4043-4051, 2014.

35. Zhu T, Zhang W, Xiao M, Chen $\mathrm{H}$ and Jin $\mathrm{H}$ : Protective role of andrographolide in bleomycin-induced pulmonary fibrosis in mice. Int J Mol Sci 14: 23581-23596, 2013.

36. Dogra C, Changotra H, Mohan S and Kumar A: Tumor necrosis factor-like weak inducer of apoptosis inhibits skeletal myogenesis through sustained activation of nuclear factor-kappaB and degradation of MyoD protein. J Biol Chem 281: 10327-10336, 2006.

37. Everhart MB, Han W, Sherrill TP, Arutiunov M, Polosukhin VV, Burke JR, Sadikot RT, Christman JW, Yull FE and Blackwell TS: Duration and intensity of NF-kappaB activity determine the severity of endotoxin-induced acute lung injury. J Immunol 176: 4995-5005, 2006. 